\title{
Study of Monsoonal Features Using Regional Climate Model over Heterogeneous Monsoon Dominated Region
}

\author{
Rohit Srivastava ${ }^{1, *}$ and Ruchita Shah $^{1}$ \\ ${ }^{1}$ Pandit Deendayal Petroleum University, Raisan, Gandhinagar - 382007, India
}

\begin{abstract}
Global warming is an increase in average global temperature of the earth which lead to climate change. Heterogeneity in the earth-atmosphere system becomes difficult to capture at low resolution $\left(1^{\circ} \mathrm{x} 1^{\circ}\right)$ by satellite. Such features may be captured by using high resolution model such as regional climate model $\left(0.5^{\circ} \mathrm{x} 0.5^{\circ}\right)$. This type of study is quite important for a monsoon dominated country like India where IndoGangetic Plains (IGP) faces highest heterogeneity due to its geographic location. Present study compares high resolution model features with satellite data over IGP for monsoon season during a normal rainfall year 2010 to understand the actual performance of model. Almost whole IGP simulates relative humidity (RH) with wide range ( $50-100 \%)$, whereas satellite shows it with narrow range ( 60-80\%) during September, 2010. Thus model is able to pick the features which were missed by satellite. Hence further model simulation extends over India and adjoining oceanic regions which simulates data of southwest monsoon with high ( 70-100\%) RH, high ( 0.4-0.7) cloud fraction (CF) and low ( 80-200 W/m²) outgoing longwave radiation (OLR) over Arabian Sea during June, 2010. Such type of study can be useful to understand heterogeneity at regional scale with the help of high resolution model generated data.
\end{abstract}

\section{Introduction}

Global warming is described as gradual rise in the average temperature of the Earth's atmosphere. Its global averaged temperature has risen between $0.4-0.8^{\circ} \mathrm{C}$ over past 100 years and predicted that it could increase from $1.4-5.8^{\circ} \mathrm{C}$ by the end of $21^{\text {st }}$ century [1]. This leads to vary weather patterns and is believed to change the climate of the earth. Rise in surface temperature as well as sea surface temperature are such effects of global warming which directly and indirectly affects our earth atmosphere system. Precipitation patterns in tropical and sub-tropical regions are governed by sea surface temperature [2]. Rising temperature increase humidity in the atmosphere which in turn may perturb cloud properties and hence cloud formation processes.

Relative humidity can be measured as a quantity of water present in the air as compared to the maximum amount of water the air can absorb, expressed in percentage. It has seasonal dependency and highly associated with temperature and geographical location. Warmer air holds more moisture than cooler air and hence it may affect weather patterns. Oceanic regions as well as coastal areas have high humidity due to rising rate of evaporation [3]. Generally over oceans, hygroscopic nuclei takes less time to condense and hence formation of cloud droplets. Many researchers at global level have proved that cloud and rain processes can be understood well with the help of cloud microphysical properties [4]. A few such studies have been done at global level but regional high resolution studies, which are more important to understand clouds, are sparse. In this system, clouds are one of the significant parameter which requires better understanding in order to indicate and to predict the weather patterns and hence climate change. Here, a cloud macrophysical property named CF is studied to understand its correlation with $\mathrm{RH}$ and its dependency on OLR.

OLR also has a significant impact of global warming which influences the earth's radiation budget. OLR can reemit back onto the earth's surface, can transmit through atmospheric window, can absorb by the atmosphere and also can get emit by atmosphere into the space. Thus presence (high CF) as well as absence (low CF) of cloud would lead to perturb OLR and hence earth radiation budget. Hence present study focuses to study atmospheric parameters such as RH, CF and OLR for monsoon season (June-September) during a normal rainfall year 2010 with the help of remote sensing and model simulation data over IGP and India.

Satellite retrieves data with limited spatial and temporal resolution and hence regional variations are not able to capture. Such phenomena's can be investigated with the help of high resolution models. Most of the models are categorized under General Climate Model (GCM) and Regional Climate Model (RegCM). GCM incorporates runs over wide region whereas RegCM runs over a specific region such as central India. Earlier research study demonstrates that RegCM's are more reliable than GCM to examine weather and climate conditions [5]. Various studies about RegCM have reported to improve simulation at regional scale which

Corresponding author: rohit.prl@gmail.com 
regulates the spatial distribution of climate variables [610]. Earlier research studies on model simulation have shown to improve understanding of climate processes such as cloud-radiation forcing, cumulus convection and land-surface processes [11-18]. Such high resolution studies are quite important for a monsoon dominated country like India, where in $70 \%$ of the population depends on agriculture for their livelihood [19]. Any monsoonal changes would indirectly affect cloud properties and its formation processes.

In India, IGP is the major river basin having most fertile farmed zones situated in the foothills of Himalayas which occupies almost $15 \%$ of the total geographical area of Indian subcontinent [20]. It produces about $50 \%$ of the total food grains for $40 \%$ of the population of the country [20]. Almost $53 \%$ of the total area cultivates rice and wheat crops and hence pronounced as "food basket" of India [21]. Moreover, boundary layer ozone and its precursors show an elevated concentration over IGP as compared to other surrounding regions [22-23]. Climate of IGP is associated with monsoon rain and any change in this factor lead to affect hydrology, soil fertility, food production and settlement pattern of IGP. Movement of sand through wind from Thar Desert is also one of the reason to vulnerable the climate over IGP [24]. Thus to understand diversified weather over IGP, present study focuses on high resolution model features and later on compared them with satellite retrievals to strengthen the model results. RegCM 4.4 runs further over India and its adjoining oceanic regions to develop correlation between $\mathrm{RH}$ (at $850 \mathrm{hPa}$ ), CF and OLR during monsoon season for a normal rainfall year 2010. Such actual phenomena's of normal rainfall year may help to understand seasonal heterogeneity and regional climate variability. In future, similar studies can be done by taking long term data and more number of parameters.

\section{Data and Methodology}

IGP is among the most likely agricultural productive region where temperature and precipitation are likely to change due to its geographic location [25]. This region get influence by extreme weather events such as fog occurrence, heavy rain, cloud bursts and floods due to climate change and are likely to increase [26]. Varying weather patterns and climatic effects create heterogeneity in the system at regional scale which can be investigated by using three atmospheric parameters such as RH, CF and OLR with the help of high resolution RegCM 4.4. These reproduced features are compared with satellite retrievals during monsoon season (June-September) for a normal rainfall year-2010, to know the actual scenario over IGP $\left(75^{\circ} \mathrm{E}-89^{\circ} \mathrm{E}\right.$ to $20^{\circ} \mathrm{N}-32^{\circ} \mathrm{N}$ ), as shown in Figure 1. Further these model features are simulated over India and its adjoining oceanic regions $\left(63^{\circ} \mathrm{E}-96^{\circ} 5^{\prime} \mathrm{E}\right.$ to $\left.5^{\circ} \mathrm{N}-33^{\circ} 5^{\prime} \mathrm{N}\right)$, to study their dependency on each other.

AIRS (Atmospheric Infrared Sounder) is an imaging instrument on-board Aqua satellite in 2002. Satellite data such as RH (\%) at $850 \mathrm{hPa}$, total CF and OLR $\left(\mathrm{W} / \mathrm{m}^{2}\right)$ of daily variation (level 3 ) are deployed with $1^{\circ} \times 1^{\circ}$ spatial resolution for monsoon season of 2010 [27].

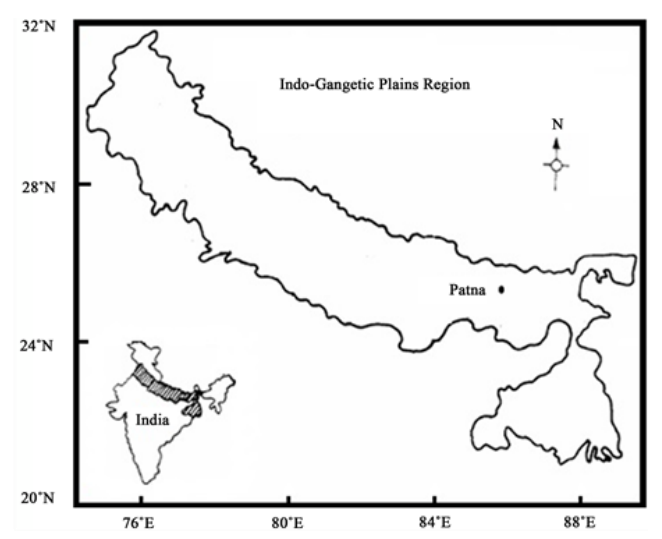

Fig. 1. Indo-Gangetic Plains (IGP) of India

In case of RegCM 4.4, it configured with a single domain of horizontal resolution of $60 \mathrm{~km}, 18$ vertical levels and with model top at $50 \mathrm{hPa}$. Initial atmospheric fields and time varying boundary conditions are derived from the National Centers for Environmental Prediction (NCEP) Reanalysis (NNRP1) with the grid of $2.5^{\circ} \times 2.5^{\circ}$ There are various convection schemes in RegCM 4.4, among them Grell convective scheme is implemented, as it has performed better than other convection schemes to simulate south west monsoon [28-30]. Similar parameters are simulated with the help of model to investigate their features at high resolution.

\section{Results and Discussion}

Present study compares RH, CF and OLR by using model simulation and satellite measurements for a monsoonal month of September, 2010 over IGP. RH at $850 \mathrm{hPa}$ is shown over IGP of India with the help of satellite and model in figure $2 \mathrm{a}$ and $2 \mathrm{~b}$ respectively. Almost whole IGP show variation of $\mathrm{RH}$ with narrow range $(\sim 60-80 \%)$, whereas high resolution simulated patches varies with wide range $(\sim 50-100 \%)$ (Figure $2 \mathrm{a}$ and $2 \mathrm{~b}$ ). Along with RH, CF and OLR are also studied to understand the overall atmospheric scenario as well as to investigate high resolution features.

Most of the IGP region reproduces CF by a big patch with $\sim 0-0.7$, whereas it interpolates from $\sim 0.6$ to $\sim 0.9$ (Figure $2 \mathrm{c}$ and $2 \mathrm{~d}$ ). High as well as low values of $\mathrm{CF}$ affects OLR. IGP gets simulates with a patch of OLR which show variation of $\sim 100-300 \mathrm{~W} / \mathrm{m}^{2}$. Similar patch is captured by $\sim 225-275 \mathrm{~W} / \mathrm{m}^{2}$ with the help of satellite (Figure $2 \mathrm{e}$ and $2 \mathrm{f}$ ). Such variations in these parameters is may be due to their different spatial resolutions. It is observed that model is able to depict the features at high resolution, which has been not captured by the satellite. Similar type of observations are also observed during remaining months of monsoon-June, July and August for the year 2010. Such high resolution simulated features could be more helpful in understanding weather patterns and hence climate change. 

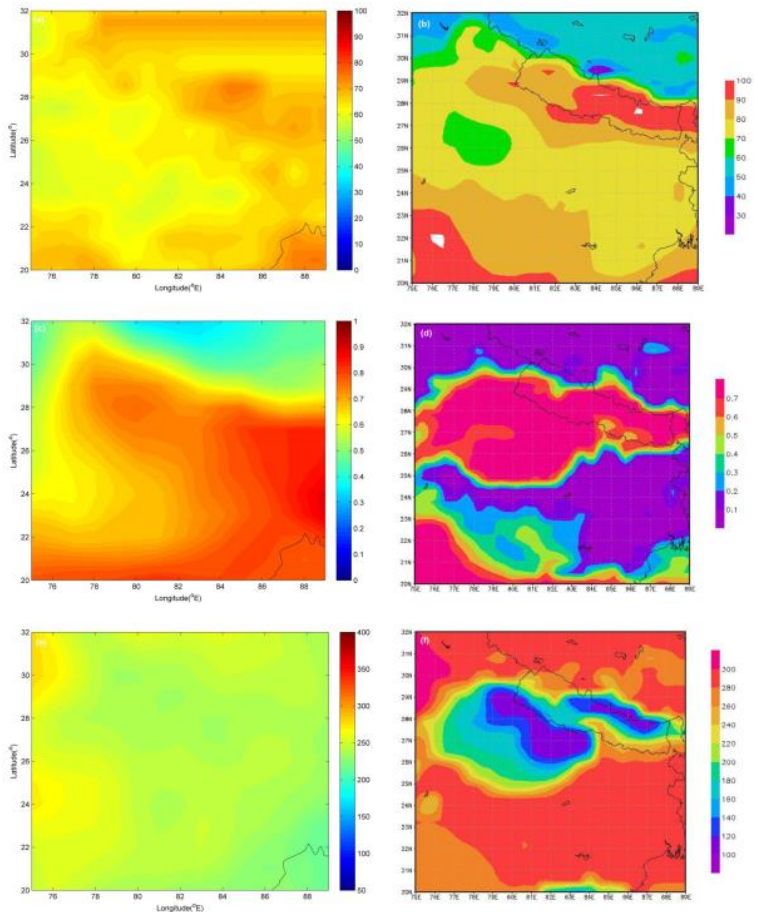

Fig. 2. Daily variation of (a) RH (\%) at $850 \mathrm{hPa}$ by satellite, (b) $\mathrm{RH}(\%)$ at $850 \mathrm{hPa}$ by RegCM 4.4 , (c) CF by satellite, (d) $\mathrm{CF}$ by RegCM 4.4, (e) OLR (W/m²) by satellite and (f) OLR $\left(\mathrm{W} / \mathrm{m}^{2}\right)$ by RegCM 4.4 over IGP for the month of September, 2010 .

RH plays an important role in the atmosphere and hence in varying $\mathrm{CF}$ and OLR. Model simulated features of $\mathrm{RH}$ at $850 \mathrm{hPa}$ is shown over India and its adjoining oceanic regions during monsoon. During this season, most of the oceanic regions gets covered with high values of RH, which got captured well by the model (Figure 3).
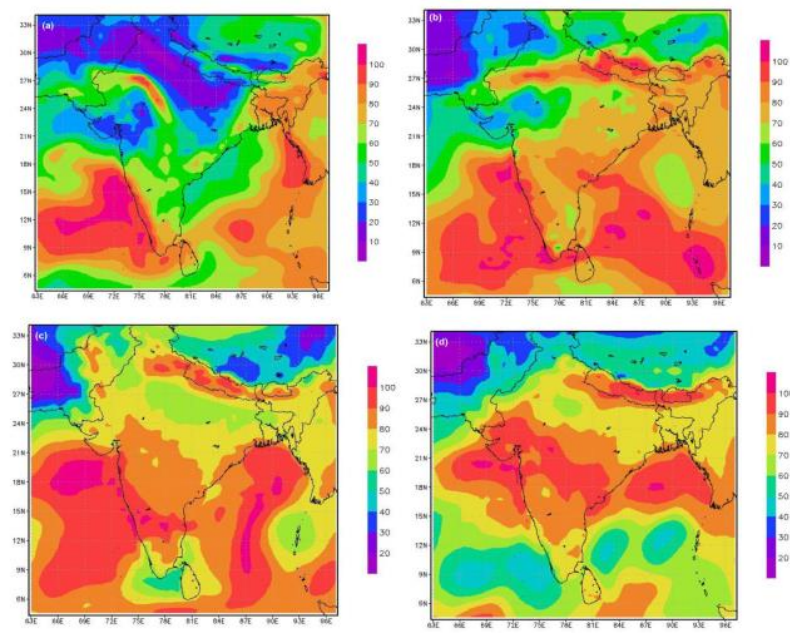

Fig. 3. Model generated features of $\mathrm{RH}(\%)$ at $850 \mathrm{hPa}$ for the month of (a) June, (b) July, (c) August and (d) September over India and adjoining oceanic regions for the year 2010.

Most of the northern part of India is covered with low values $(\sim 0-40 \%)$, whereas southern part is covered with high values $(\sim 50-100 \%)$ of $\mathrm{RH}$, which depicts the initial phase of south-west monsoon (Figure 3a). Progression of monsoonal winds is postured well by the model with high values of RH ( 80-100\%) over Arabian Sea during the month of June. Moving towards the month of July, most of the adjoining oceans of India is covered with high levels of RH ( 80-100\%) (Figure $3 \mathrm{~b})$. Moreover, coastal regions also show high values of $\mathrm{RH}$ $(\sim 60-90 \%)$ in the month of July, which gradually shifts over land regions of India and hence signifies the progression of monsoonal winds (Figure $3 \mathrm{~b}$ and $3 \mathrm{c}$ ). During the month of August, RH extends over most of the land regions of India, which later on gets withdraws in September. Patches of low RH $(\sim 40-50 \%)$ is simulated over oceanic regions and patches of high $\mathrm{RH}$ $(\sim 70-100 \%)$ is mostly simulated over land regions of India. Thus mostly all the features of south-west monsoon is simulated well by the model and hence is correlated further with the monsoonal patches of $\mathrm{CF}$.

Monsoonal features of total $\mathrm{CF}$ is simulated by RegCM to understand the effect of cloud on OLR. Signature of monsoon is clearly seen with the high values of CF mostly over all the regions of India (Figure 4). Patch of high RH matches well with high CF over Arabian Sea as well as over Western Ghats and depicts the onset of south-west monsoon (Figure $3 \mathrm{a}$ and $4 \mathrm{a}$ ).
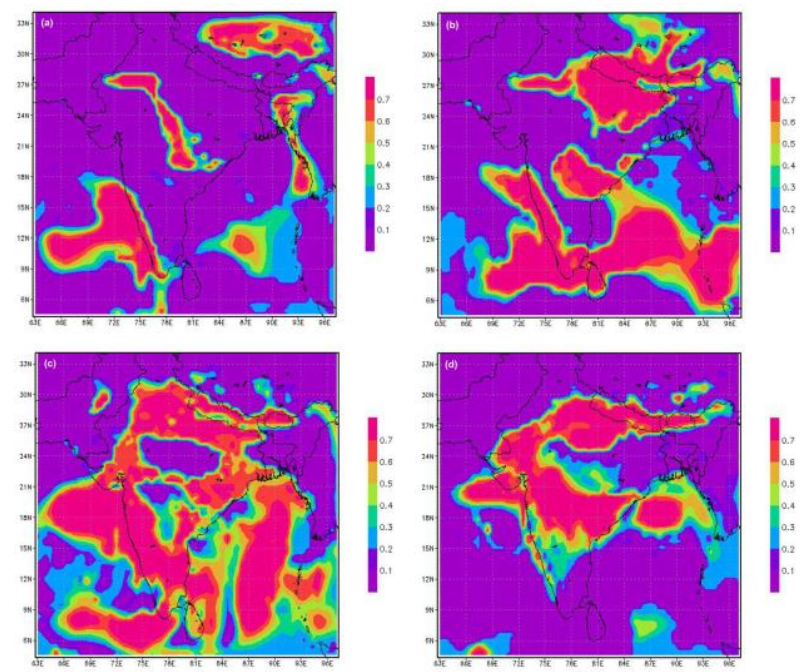

Fig. 4. Model generated features of $\mathrm{CF}$ for the month of (a) June, (b) July, (c) August and (d) September over India and adjoining oceanic regions for the year 2010 .

Moreover big patch of CF ( 0.1-0.7) matches with RH $(\sim 60-90 \%)$ over mid and western part of Bay of Bengal (Figure $3 \mathrm{a}$ and $4 \mathrm{a}$ ). Small patch over northwestern part and central India gets simulated with high CF ( 0.7-0.8) and high humidity levels ( 80-100\%) (Figure $3 \mathrm{a}$ and $4 \mathrm{a}$ ). Almost whole land regions of India is simulated with cloud free condition during the month of June. Similarly, presence of cloud gets depicted well with high values of CF in the month of July, August and September (Figure 4b, 4c and 4d). Almost all these simulated features matches well with $\mathrm{RH}$ and thus $\mathrm{CF}$ and RH shows good correlation. Onset of south west 
monsoonal winds, its progression over land regions and its departure phase from land are captured with high values of $\mathrm{CF}$ and $\mathrm{RH}$ (Figure 3 and 4). Such type of simulated features may help to understand the effect of cloud in the atmosphere.
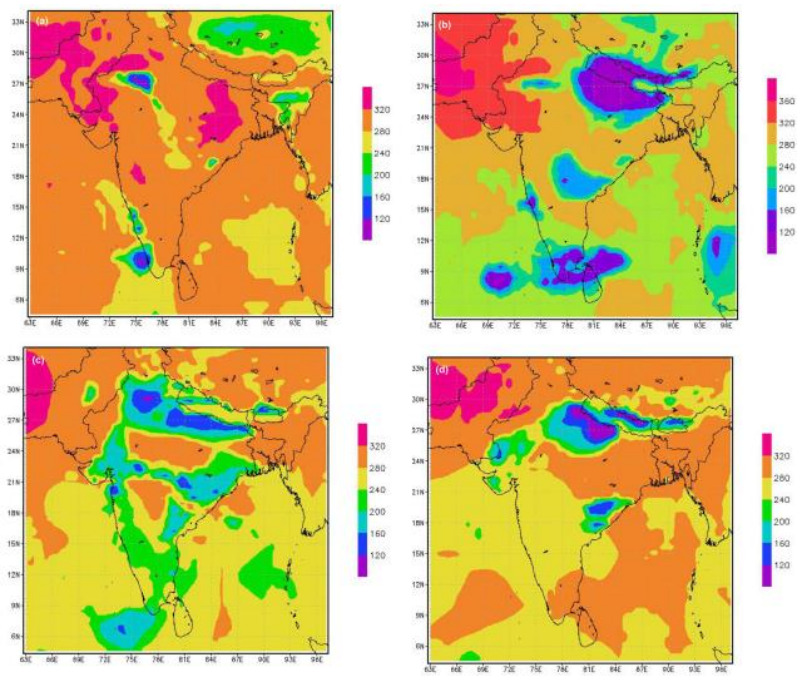

Fig. 5. Model generated features of OLR $\left(\mathrm{W} / \mathrm{m}^{2}\right)$ for the month of (a) June, (b) July, (c) August and (d) September over India and adjoining oceanic regions for the year 2010.

To study the role of CF on OLR, further simulation of total OLR during monsoonal months (June-September) are shown in Figure 5. Like clouds, OLR also plays a significant role in balancing the radiation budget of the earth. Cloud usually traps the OLR which gets simulated well by the model. Most of the Indian region is simulated with high values of OLR $\left(\sim 300 \mathrm{~W} / \mathrm{m}^{2}\right)$ during the month of June, which coordinates well with null values of $\mathrm{CF}$. On the other hand, a small patch of high CF ( 0.6-0.7) with low OLR ( 100-150 W/m²) over central India and north-western part near Rajasthan (Figure 4a and 5a). During July, patches of low OLR is simulated with high CF over central part of IndoGangetic Plains, central Arabian Sea and southern tip of India (Figure $4 \mathrm{~b}$ and $5 \mathrm{~b}$ ). Similar kind of correlation is observed for August and September which also show promising results (Figure 5c and 5d).

\section{Summary}

Present study show RH, CF and OLR for monsoon season (June-September) during a normal rainfall year 2010 over IGP of India, Indian subcontinent and its adjoining oceanic regions. Heterogeneity in the earthatmosphere system due to global warming was captured well by RegCM 4.4 as compared to satellite. During a month of September, satellite data interpolates CF with narrow range $(\sim 0.6-0.9)$ whereas it reproduced with wide range $(\sim 0-0.7)$ over IGP. Along with $\mathrm{CF}$, features of $\mathrm{RH}$ as well as OLR are compared for remaining months of monsoon (June, July and August), which also show promising results. These comparative observations signifies high resolution features by the model which are not been captured well by satellite. Later on, this study was extended over India and its adjoining oceanic regions by utilizing simulated features of $\mathrm{RH}, \mathrm{CF}$ and OLR. Progression of southwest monsoon gets capture with high values $(\sim 70-100 \%)$ of $\mathrm{RH}$, high values $(\sim 0.4-$ $0.7)$ of CF and low values of OLR $\left(\sim 80-200 \mathrm{~W} / \mathrm{m}^{2}\right)$ over Arabian Sea during June, 2010. Almost all the monsoonal features were captured with low/high RH and low/high CF over India and its adjoining oceans, which signifies that rising $\mathrm{RH}$ may enhance cloud formation by evaporation. On the other hand, low/high values of $\mathrm{CF}$ matches with high/low values of OLR, which depicts that most of the OLR gets trapped by clouds. This study needs to be clarify by using long term data which may strengthen these results. Research carried out in this field may help to understand heterogeneity at smaller scale especially over monsoon dominated regions by using high resolution models. Such type of study may help to understand the effects of global warming such as variation in earth's radiation budget, seasonal influence of atmospheric parameters on the system and hence climate change.

Authors thank Department of Science and Technology-Science and Engineering Research Board, India for granting Fast Track Project (ECR/2017/002000).

\section{References}

1. IPCC, "Climate Change 2014 Synthesis Report Summary Chapter for Policymakers", IPCC, 1-31, (2014).

2. Widlansky, M. J., Annamalai, H., Gingerich, S. B., Storlazzi, C. D., Marra, J. J., Hodges K. I. and Kitoh, A. A., "Tropical Cyclone Projections: Changing Climate Threats for Pacific Island Defense Installations", Weather. Clim. Soc., 11, 3-15 (2019).

3. Martínez-Castro,D.,Vichot-Llano,A.,Bezanilla-Morl ot, A., Centella-Artola, A., Campbell, J., Giorgi, F., Viloria-Holguin, C.C. "The performance of RegCM4 over the Central America and Caribbean region using different cumulus parameterizations", Clim. Dyn. (2017).

4. Zeng, S., Riedi, J., Trepte, C. R., Winker, D. M. and Hu., Y. X., "Study of global cloud droplet number concentration with A-Train satellites", Atmos. Chem. Phys., 14, 7125-7134 (2014).

5. Sharma, T., Gusain, A. and Karmakar, S. "Future Hydrologic Scenarios in India Under Climate Change", Clim. Chang. Signals Response, 39-59 (2019).

6. Pathak, P. A. B., Bhuyan, F. S. P. K. and Giorgi, F., "Obtaining best parameterization scheme of RegCM 4 . 4 for aerosols and chemistry simulations over the CORDEX South Asia", Clim. Dyn. (2019).

7. Ahn, K. and Kim, Y., "Incorporating Climate Model Similarities and Hydrologic Error Models to Quantify Climate Change Impacts on Future Riverine", J. Hydrol. (2018). 
8. Nengker,T.,Choudhary,A., Dimri, A. P., Assessment of the performance of CORDEX-SA experiments in simulating seasonal mean temperature over the Himalayan region for the present climate: Part I, Springer Berlin Heidelberg (2017).

9. Wang, L., Cheung, K. K. W., Tam, C-Y, Taib, A. P. K. and Lid, Y., "Evaluation of the Regional Climate Model over the Loess Plateau of China", Int. J. Climatol., 38, June, 35-54 (2018).

10. Gibba, P., Sylla, M. B., Okogbue, E. C., Gaye, A. T., Nikiema, M. and Kebe, I., "State-of-the-art climate modeling of extreme precipitation over Africa: analysis of CORDEX added-value over CMIP5", Theor. and Appl. Climatol., 1-17 (2018).

11. Pan Z., Segal, M., Turner, R. and Takle, E., "Model simulation of Impacts of Transient surface wetness on summer rainfall in the united states midwest during drought and flood years", Mon. Weather Rev., 123, 1575-1581 (1995).

12. Dudek, M.P., Zhong Liang, X. and Wang, W.-K., "A regional climate model study of the scale dependency of cloud-radiation interactions", $J$. Clim., 9,1221-1234 (1996).

13. Bosilovich, M.G. and Sun, W.-Y., "Numerical Simulation of the 1993 Midwestern Flood: Land Atmosphere Interactions", J. Clim., 12, 1490-1505 (1999).

14. Schar, C., Luthi, D. and Beyerle, U., "The Soil Precipitation Feedback: A Process Study with a Regional Climate Model The Soil - Precipitation Feedback: A Process Study with a Regional Climate Model”, J. Clim., 0442, March, 722-741 (1999).

15. Barros, A. P. and Hwu, W. , "A study of landatmosphere interactions during summertime rainfall using a mesoscale model", J. Geophys. Res. Atmos., 107, D14, 1-18 (2002).

16. Sen, O.L., Wang, Y., and Wang, B., "Impact of Indochina Deforestation on the East Asian Summer Monsoon", J. Clim., 17, 1366-1380 (2004).

17. Sen, O. L, Wang, B. and Wang, Y., "Impacts of Regreening the Desertified Lands in Northwestern China: Implications from a Regional Climate Model Experiment", J. Meterological Soc. Japan, 82, October, 1679-1693 (2004).

18. Wang, Y., Xie, S-P, Wang, B. and Xu, H., "LargeScale Atmospheric Forcing by Southeast Pacific Boundary Layer Clouds : A Regional Model Study", J. Clim., 18, 934-951 (2005).

19. Khan, S. A., Kumar, S., Hussain, M. Z., \& Kalra, N. "Climate Change, Climate Variability and Indian Agriculture: Impacts Vulnerability and Adaptation Strategies. In R. Allan, U. Forstner, \& W. Salomons (Eds.), Clim. Change and Crops: Springer (2009).

20. Koshal, A. K. "Changing Current Scenario of Rice-Wheat System in Indo-Gangetic Plain Region of India", Int. J. of Sci. and Res. Pub.", 4, 3, 1-13 (2014).
21. Pal, D.K., Bhattacharyya, T. Srivastava, P., Chandran, P. and Ray, S.K. "Soils of the IndoGangetic Plains:their historical perspective and management", Curr. Sci., 96, 9,1193-1202 (2009).

22. Rupakheti, D., Kang, S., Rupakheti, M., Zhang, Q., Chen, P. and Yin, X., "Long-term trends in the total columns of ozone and its precursor gases derived from satellite measurements during 2004 - 2015 over three different regions in South Asia: IndoGangetic Plain , Himalayas and Tibetan Plateau," Int. J. Remote Sens., 1-21 (2018).

23. Putero, D. , Marinoni, A., Bonasoni, P., Calzolari, F., Rupakheti, M. and Cristofanelli, P., "Black Carbon and Ozone Variability at the Kathmandu Valley and at the Southern Himalayas: A Comparison between a 'Hot Spot' and a Downwind High-Altitude Site", Aero. and Air Qual. Res., 18, 3, 623-635 (2018).

24. Ali, K., Momin, G. A., Safai, P. D., Chate, D. M., and Rao, P. S. P., "Surface ozone measurements over Himalayan region and Delhi, North India", $J$. of Atm. Chem., 33, 2-5 (2018).

25. Saini, H. S. "'Climate Change and its Future Impact on the Indo-Gangetic Plain (IGP) Climate Change and its Future Impact on the Indo-Gangetic Plain (IGP)", Earth Sci. India, 1, 3,138-147 (2016).

26. New, M., Rahiz, M. and Karmacharya, J. "Climate Change in Indo Gangetic Agriculture: Recent Trends , Current Projections , Crop, Climate Suitability, and Prospects for Improved Climate Model Information",Copenhagen:CGIAR Research Program on Climate Change, Agriculture and Food Security (CCAFS) (2012).

27. Acker, J. G. and Leptoukh, G., "Online Analysis Enhances Use of NASA Earth Science Data", Eos, Trans. AGU, 88, 2, 14-17 (2007).

28. Sharma, D., Singh, D. and Kaskaoutis, D. G., "Impact of Two Intense Dust Storms on Aerosol Characteristics and Radiative Forcing over Patiala , Northwestern India", Adv. in Meterology, 956814 (2012).

29. Pattnayak, K.C. and Dash, S. K., “Annual cycles of circulation and precipitation over India simulated by a Regional Climate Model", Vayumandal, (2014).

30. Grell, G. A., "Prognostic Evaluation of Assumptions used by cumulus parameterization", Mon. Weather Rev., 121, 764-787 (1993). 